\title{
PRESIDENTE PRUDENTE - SP: UM POUCO DE MEMORIA HISTÓRICA
}

Mariane Celeste, Michelle Fernandes, Adriana Hashinaga, Yeda Ruiz Maria

Universidade do Oeste Paulista - UNOESTE, Curso de Arquitetura e Urbanismo, Presidente Prudente, SP. E-mail: yeda rm@hotmail.com

\section{RESUMO}

O trabalho tem o intuito de analisar a historia da cidade de Presidente Prudente, para o estudo do quadrilátero central. $O$ estudo permitira uma melhor compreensão da evolução social e física da região, e assim possibilitar o entendimento da situação atual da cidade, e consequentemente do quadrilátero central, tanto em aspectos físicos quanto sociais. $\mathrm{O}$ trabalho foi desenvolvido através de pesquisas em textos, livros e imagens, e para uma melhor organização dos fatos históricos, foi elaborada uma linha do tempo a partir dos primeiros acontecimentos que envolviam o surgimento da cidade de Presidente Prudente até a situação atualmente. Ao longo do estudo pode se concluir que o mal planejamento e o desenvolvimento desordenado e inesperado da cidade teve consequências até os dias atuais.

Palavras-chave: Quadrilátero central. História. Pioneiros. Presidente Prudente - SP.

\section{PRESIDENTE PRUDENTE - SP: A MEMORY OF LITTLE HISTORY}

\begin{abstract}
The research article aims to analyze the history of the city of Presidente Prudente, to study the central quadrangle. Such research will enable a better understanding of social and physical development of the region, and thus make possible the understanding of the current situation of the city, and therefore the central quadrangle, both in physical aspects like social. The work was developed through research in texts, books and pictures, for a better organization of historical facts, a timeline from the first events involving the appearance of the city of Presidente Prudente until the situation today was developed. Throughout the study it can be concluded that the poor planning and disorderly and unexpected development of the city had consequences up to the present day.
\end{abstract}

Keywords: central quadrangle . History. Pioneers. Presidente Prudente - SP. 


\section{INTRODUÇÃO}

O quadrilátero central de Presidente Prudente - SP hoje apresenta diversos problemas derivados da falta de planejamento ocorrida no surgimento da cidade. Atualmente o centro da cidade é um ponto de grande densidade de pessoas durante o dia, visto que o desembarque de varias linhas do transporte público, o intenso comércio, e desordenado fluxo de carros ocorrem nesta área central de Presidente Prudente. Portanto, analisando a forma que a cidade se desenvolveu pode-se notar alguns fatores que influenciaram diretamente na situação do quadrilátero central nos dias atuais.

Sendo assim este trabalho tem como justificativa o uso da análise dos processos temporais que modificaram a cidade de Presidente Prudente - SP desde a sua fundação, fomentando assim o desenvolvimento sustentável no futuro da cidade.

No objetivo de divulgar e questionar a história da cidade de Presidente Prudente -SP, tal trabalho pretende ser um meio para que os leitores possam aprimorar sua visão crítica diante de tantos fatos históricos.

A metodologia utilizada baseia-se em pesquisa bibliográfica, documentos oficiais públicos e visitas in loco.

\section{PRESIDENTE PRUDENTE - SP TEM HISTÓRIA}

De acordo com dados disponibilizados pelo museu municipal (2015), no ano de 1893 foi aberto um caminho entre Campos Novos do Paranapanema e o Rio Paraná, para se fazer ligação com o Mato Grosso. Nesse espaço se fez a expansão das plantações de café que em consequencia ampliou o espaço e promoveu a ocupação da região do extremo Oeste Paulista.

Os grandes latifundiários do café das regiões mais antigas se dirigiram para o Oeste Paulista. Assim o sertão do Paranapanema foi sendo compartimentado em latifúndios cafeeiros e pequenas propriedades exploradas pelo colono e sua família. Ao mesmo tempo, a ferrovia Estrada de Ferro Sorocabana - expandiu-se para a região, sendo um importante elemento de infraestrutura da economia cafeeira, pois significava transporte rápido, seguro e barato do café para os centros maiores. A ferrovia favoreceu a penetração do sertão, os loteamentos, a ocupação e o aproveitamento do solo. Ao longo da linha férrea multiplicaram-se os núcleos urbanos, dentre os quais Presidente Prudente (MUSEU MUNICIPAL, 2015).

Neste contexto se entende que o desenvolvimento de Presidente Prudente - SP foi orientado pela ferrovia, enquanto esta foi a principal via de circulação de pessoas e mercadorias. A 
escolha do sítio urbano está ligada ao traçado da Estrada de Ferro Sorocabana, que também seguiu a linha dos espigões.

De acordo com Resende (1992), em 1917 se instalou a Estrada de Ferro Sorocabana, a partir da qual foi demarcada o território de um núcleo urbano, nascendo assim a Vila Goulart, em 14 de setembro de 1917.

Com a inauguração da estação de Presidente Prudente, em 19 de janeiro de 1919, o povoamento foi aumentando tanto na área rural quanto na área urbana. Surge assim a Vila Goulart ( a oeste) e a Vila Marcondes (a leste), ambas crescendo paralelas à estação de ferro (RESENDE,1992).

Segundo Whitacker (1997, p.130), "esses dois núcleos, que originaram posteriormente a cidade, possuíam, cada qual, características de centralidade que vieram a se evidenciar, ou a involuir, ao largo do tempo, bem como do crescimento da malha urbana. A situação destes núcleos, ladeando a estrada de ferro, orientou o processo de expansão territorial da cidade, e a posição da estação vieram a ter grande importância no desenvolvimento ulterior de suas funções centrais.

A vila Goulart cresceu mais que a vila Marcondes, tal fato pode se dar por alguns motivos:

- A vila Goulart, por ter sido implantada anterior à estação ferroviária, influenciou a localização da frente dos vagões dos trens, que se abriam para o lato oeste, lado da vila Goulart.

- Já a vila Marcondes, por ter tido sua implantação posterior, e uma vez que o núcleo Goulart era de propriedade de colonização concorrente, ocupou a área do lado oposto da ferrovia.

- Outro fator que pode-se agregar é a topografia da vila Marcondes, que é cada vez mais acidentada conforme se segue distanciando da estrada de ferro. Enquanto a topografia da vila Goulart é mais suave, nivelada.

No entanto, as duas vilas cresciam e prosperavam paralelas à estrada de ferro. A vila Goulart foi paulatinamente assumindo características de centro da cidade, enquanto a vila Marcondes, primeiramente, também com característica centrais, passou a concentrar as suas funções de suporte à ocupação das terras rurais.

\section{OS ANOS PASSAM}

Em 1925, após cinco anos de insistência, Goulart consegue a instalação do primeiro grupo escolar da cidade, localizado na confluência das avenidas Washington Luiz e a Avenida Coronel 
Marcondes; surgindo então o segundo grupo escolar em 1929 , em um prédio alugado na Rua Newton Prado, a atual Rua Felício Tarabay (RESENDE, 1992).

Em 1930, foi fundado o Ginásio São Paulo, que foi a primeira resposta efetiva no ensino secundário na cidade, cinco anos depois viria a surgir o terceiro grupo escolar de Presidente Prudente, dividindo o prédio com o segundo grupo escolar; um avanço para a cidade, embora nesse período a maioria das ruas não estivessem calçadas, também não havendo guias, sarjetas, sistema de água, luz, telefone, esgoto, matadouro ou sequer assistência funerária (RESENDE, 1992).

Já em 1933, a Praça 9 de Julho foi construída pelo então Prefeito Felício Tarabay (WHITACKER, 1997, p.138), e era vista como "O jardim de prudente". Uma obra grandiosa para a época e para a cidade. E um marco de centralidade.

Com o aumento da população e visando uma demonstração de imponência, em 1936 começa a construção do templo definitivo da Igreja São Sebastião, marco da cidade até os dias de hoje, localizada atualmente na praça 9 de Julho.

Em 1937 o Colégio Cristo Rei abre suas portas para oferecer o curso secundário á população, tendo aulas de primário, pré-primário, pintura, desenho e piano. Nos dias atuais o colégio é de ensino particular e oferece aulas do ensino infantil até o ensino médio.

Com os diversos grupos escolares na cidade, os seus três primeiros grupo se unem e criam um único grupo, com o nome de Grupo Escolar Profo Adolpho Arruda Mello, e a esta altura, “Presidente Prudente já era considerada uma rede escolar elementar e secundária mais completa da região." (RESENDE, 1992).

Em 1940 começam as obras para a construção do Colégio IE Fernando Costa, mais um grupo escolar para Presidente Prudente - SP localizado na Av. Washington Luiz, e ao mesmo tempo o Bar Cruzeiro do Sul é inaugurado na esquina Nicolau Maffei com a Joaquim Nabuco.

Em 1943, abre-se o Hotel Municipal de Presidente Prudente. Originalmente, o Antigo Hotel Municipal, foi construído para ser a segunda casa de saúde de Presidente Prudente, com o nome de Casa de Saúde São Paulo, de propriedade do Dr. Romeu Leão Cavalcanti. "A presença de médicos na região era um atrativo para compradores dos lotes, razão pela qual foi implantado em local privilegiado, de fácil acesso a Estação da Estrada de Ferro Sorocabana." (HIRAO, 2011). Atualmente o hotel está sem uso, pois foi descaracterizado em partes da fachada 1

Em 1950, a construção do antigo Fórum, localizado na Av. Cel Marcondes, teve início, na mesma época, chega á Prudente seus primeiros edifícios, levando a população á uma busca por 
este "novo conceito de morar". Velhas casas construídas em datas amplas iam sendo demolidas e os espaços se tornavam convidativos para novos empreendimentos(RESENDE, 1992).

Em 1954, a Av. Cel. Marcondes acabava na rua da Santa Casa de Misericórdia de Presidente Prudente; entretanto mesmo com o avanço ao longo dos anos, em 1970 a infraestrutura da cidade era precária.

\section{CONCLUSÃO}

Com o desenvolvimento desenfreado que o quadrilátero central sofre, suas características iniciais estão se modificando com as camadas do tempo e então nele, teoricamente falando, fez-se uma área "descolada" do restante da cidade; suas casas térreas foram desaparecendo dando lugar aos edifícios, e o comércio apossando-se das velhas residências; já suas ruas tornaram-se disputadas pelos carros e motos, deixando o pedestre espremido em calçadas, com única opção de passeio em seu calçadão impermeável.

Cidades inevitavelmente sofrem mudanças, assim como a sociedade, e no caso de Presidente Prudente não foi diferente, o que nasceu em uma disputa de terras e poderio coronelista, hoje coloca-se como polo regional de desenvolvimento e cultura, mas novamente, como em diversas cidades, a infraestrutura e consequentemente a apropriação de espaço da sociedade para com sua cidade tem sido prejudicada pelas ações de descaso público e social, haja vista o caso do museu municipal, logo, se faz necessário que o cidadão tome seu lugar na sociedade como (re)agente de sua história, á começar por conhecer seu próprio passado.

\section{REFERÊNCIAS}

HIRAO, Helio.O Antigo Hotel Municipal de Presidente Prudente Demolição do Edifício e Descaracterização da Paisagem do Centro Histórico. V. 5, N² 2, p. 128 -143, 2011.

RESENDE, B. Raízes Prudentinas - Vol. 1. São Paulo: Senac,1992

MUSEU MUNICIPAL. Site do Museu Municipal de Presidente Prudente. Disponível em: <http://museu.presidenteprudente.sp.gov.br/historia.php\#> Acesso em: 03 de Abril de 2015.

WHITACKER, A. M. A produção do espaço urbano em Presidente Prudente: Uma discussão sobre a centralidade urbana. 1997. 318f. Dissertação (Mestrado de Geografia - Área de Concentração: Desenvolvimento Regional e Planejamento Ambiental) - Faculdade de Ciências e Tecnologia, Universidade Estadual Paulista "Julio de Mesquita Filho", Presidente Prudente. 